\title{
Spectral Entropy Parameters during Rapid Ventricular Pacing for Transcatheter Aortic Valve Implantation
}

\author{
Tadeusz Musialowicz ${ }^{1, *}$, Antti Valtola ${ }^{2}$, Mikko Hippeläinen ${ }^{2}$, Jari Halonen ${ }^{2}$ and Pasi Lahtinen ${ }^{1}$ \\ 1 Department of Anesthesia and Operative Services, Kuopio University Hospital, Kuopio FI-70029, Finland; \\ pasi.lahtinen@kuh.fi \\ 2 Heart Centre Department, Kuopio University Hospital, Kuopio FI-70029, Finland; antti.valtola@kuh.fi (A.V.); \\ mikko.hippelainen@kuh.fi (M.H.); jari.halonen@kuh.fi (J.H.) \\ * Correspondence: tadeusz.musialowicz@kuh.fi; Tel.: +358-44717-4226; Fax: +358-1717-3377
}

Academic Editor: Osvaldo Anibal Rosso

Received: 16 December 2016; Accepted: 15 March 2017; Published: 20 March 2017

\begin{abstract}
The time-frequency balanced spectral entropy of the EEG is a monitoring technique measuring the level of hypnosis during general anesthesia. Two components of spectral entropy are calculated: state entropy (SE) and response entropy (RE). Transcatheter aortic valve implantation (TAVI) is a less invasive treatment for patients suffering from symptomatic aortic stenosis with contraindications for open heart surgery. The goal of hemodynamic management during the procedure is to achieve hemodynamic stability with exact blood pressure control and use of rapid ventricular pacing (RVP) that result in severe hypotension. The objective of this study was to examine how the spectral entropy values respond to RVP and other critical events during the TAVI procedure. Twenty one patients undergoing general anesthesia for TAVI were evaluated. The RVP was used twice during the procedure at a rate of $185 \pm 9 / \mathrm{min}$ with durations of $16 \pm 4 \mathrm{~s}$ (range 8-22 s) and $24 \pm 6 \mathrm{~s}$ (range 18-39 s). The systolic blood pressure during RVP was under $50 \pm 5 \mathrm{mmHg}$. Spectral entropy values SE were significantly declined during the RVP procedure, from $28 \pm 13$ to $23 \pm 13$ $(p<0.003)$ and from $29 \pm 12$ to $24 \pm 10(p<0.001)$. The corresponding values for RE were $29 \pm 13 \mathrm{vs}$. $24 \pm 13(p<0.006)$ and $30 \pm 12$ vs. $25 \pm 10(p<0.001)$. Both SE and RE values returned to the pre-RVP values after $1 \mathrm{~min}$. Ultra-short hypotension during RVP changed the spectral entropy parameters, however these indices reverted rapidly to the same value before application of RVP.
\end{abstract}

Keywords: spectral entropy; state entropy; response entropy; depth of anesthesia; rapid ventricular pacing; signal processing; heart; hemodynamics

\section{Introduction}

Intravenous and inhalation anesthetics act on the patient's central nervous system causing changes in the EEG patterns [1,2]. Thus, the EEG-based depth-of-anesthesia (DoA) monitors utilize a processed EEG signal and then translate it into simple numerical indices corresponding to the patient's level of consciousness during general anesthesia [3,4]. The Bispectral Index (BIS) was the first commercially available technique for monitoring the hypnotic level during anesthesia, exploiting a processed EEG-based BIS algorithm [5]. Assessment of the time-frequency balanced spectral entropy of the EEG is one of the techniques capable of monitoring the level of hypnosis during general anesthesia; it has been incorporated into the M-Entropy module (GE, Healthcare, Helsinki, Finland) [3,6].

The concept of spectral entropy originates from measurement of one of the most important metrics of the information theory called Shannon entropy $(H)$ equation [7]:

$$
H=-\sum p_{k} \cdot \log p_{k}
$$


where $p_{k}$ are the probabilities of a discrete $k$ event.

Spectral entropy, which is a measure of the hypnotic level of anesthesia, was conceptualized in Finland in 1999 by Viertiö-Oja and colleagues [8]. This assessment of entropy estimates the complexity and irregularity of the signal $[9,10]$ and quantifies the amount of disorder in the EEG frequency space. In order to optimize between time and frequency resolution, the M-Entropy module utilizes a set of window lengths chosen in such a way that each frequency component is obtained from a time window that is optimal for that particular frequency. In this way, information is extracted from the signal as fast as possible. The approach is closely related to the idea of the wavelet transformation wavelets, being wave packets with finite variable widths containing roughly constant number of variations to optimize between time and frequency resolution. The selected technique, however, combines this advantage of wavelet analysis with those of fast Fourier analysis, such as the possibility to explicitly consider the contribution from any particular frequency range, and efficient implementation in software [7].

One can compute the signal of EEG entropy through the time and frequency domain and undertake a Fourier transformation to obtain the time-frequency balanced spectral entropy [11]. Two components of spectral entropy are calculated as a measure of anesthetic adequacy. The State Entropy (SE) index is computed in a range from 0.8 to $32 \mathrm{~Hz}$ that includes the EEG dominating part of the spectrum and, as a consequence, primarily reflects the patient's cortical state during general anesthesia. The SE can range from 91 (patient fully awake) to 0 (cortical suppression-deep anesthesia) with surgical anesthesia range 40-60, with a time window $15-60 \mathrm{~s}$ between samplings. The estimation of the hypnotic effect of anesthetic drugs on the brain during general anesthesia may be based on the SE value. SE is not affected by abrupt reactions of the facial muscles because it is based on the EEG signal.

The response entropy (RE) index is computed from EEG and electromyography (EMG) dominant part of the spectrum of forehead muscles with frequency ranges from 0.8 to $47 \mathrm{~Hz}$. The RE index is a new contribution to the measurement of anesthesia depth; it has a range between 0 and 100 (patient awake). The activity of forehead muscles has been correlated with the patient's stress and vigilance. An increase in the EMG is an indicator of patient arousal, for example, in his/her response to nociception stimulation [12]. The RE entropy's shortest sampling window is $1.92 \mathrm{~s}$, which allows the RE to respond quickly during the monitoring to EMG activation (32-47 Hz). EMG is especially active during the awakened state but it may also be activated during surgery. Facial muscles may also give an early indication of emergence; this can be evident as a rapid rise in RE.

The two entropy parameters should be normalized so that RE equals SE whenever EMG power (the sum of spectral power between $32 \mathrm{~Hz}$ and $47 \mathrm{~Hz}$ ) equals zero. This way the difference between RE and SE will be an indicator of EMG activity. At this point, frequency range between $0.8 \mathrm{~Hz}$ and $32 \mathrm{~Hz}$ will be called " $R_{\text {low }}$ ", and frequency range from $32 \mathrm{~Hz}$ to $47 \mathrm{~Hz}$ will be called " $R_{\text {high }}$ ". The combined $0.8 \mathrm{~Hz}$ to $47 \mathrm{~Hz}$ frequency range will be called " $R_{\text {low }+ \text { high }}$ ". When spectral components within the range $R_{\text {high }}$ equal zero, the non-normalized entropy values $\mathrm{S}\left[R_{\text {low }}\right]$ and $\mathrm{S}\left[R_{\text {low }}+{ }_{\text {high }}\right]$ will coincide, while for normalized entropies there is $S_{N}\left[R_{\text {low }}\right]>S_{N}\left[R_{\text {low }}{ }_{\text {high }}\right]$ inequality $[7,8]$. The normalized SE entropy is calculated in the following way:

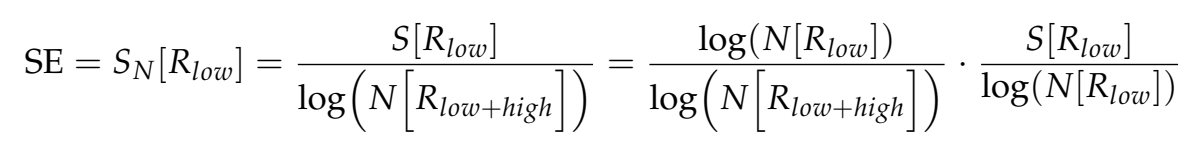

where factor $\log$ of $N\left[f_{1}, f_{2}\right]$ equals the total number of frequency components in the range $\left[f_{1}, f_{2}\right]$.

For RE, normalized entropy value is computed according to the equation:

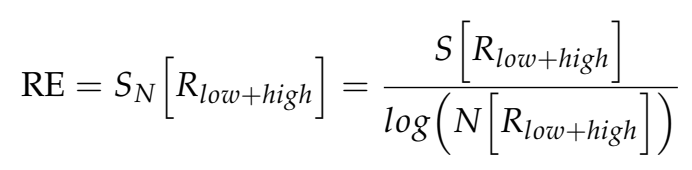




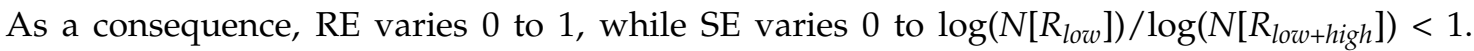
Both entropy values coincide when $P\left(f_{i}\right)=0$ for all $f_{i}$ of the $\left[R_{h i g h}\right]$ range. When there is EMG activity, spectral components of the $\left[R_{h i g h}\right]$ range are significantly different from zero and RE is higher than SE $[7,8]$.

The burst suppression ratio is also included in the measurement of deep anesthesia with $1 \mathrm{~min}$ windows and a burst suppression detection technique described by Särkelä and colleagues [13]. The Burst Suppression Ratio, (BSR; range 0\%-100\%), is defined as the percentage of time of suppressed (iso-electric, flat line) EEG periods during the last minute of analysis.

Vakkuri et al. [12] validated spectral entropy and claimed that it represented an accurate assessment of anesthesia depth with sevoflurane, propofol, or thiopental. RE and SE distinguished very well between conscious and unconscious states and exhibited high sensitivity and specificity in the detection of loss of consciousness. In studies regarding RE responsiveness to pain stimulation [14], RE increased after surgical stimulation and it was shown to predict movement in a patient after stimulation; it was also a better predictor of stimulation than the BIS index combined with hemodynamic responses [15].

\subsection{Transcatheter Aortic Valve Implantation}

The transcatheter aortic valve implantation (TAVI) is a less invasive treatment technique for patients with symptomatic aortic stenosis with contraindications preventing open heart surgery [16,17]. TAVI aims to be an alternative to open cardiac surgery for the treatment of aortic stenosis, avoiding the need for cardiopulmonary bypass. There are two different access points to the aortic valve: one through a large artery (transluminal approach), usually the femoral or subclavian artery, or alternatively surgically, via a minithoracotomy with an apical puncture of the left ventricle (transapical approach). After the insertion of a guidewire to the heart, the aortic valve ring is dilated using a balloon catheter. The new prosthetic valve is manipulated into position using X-ray machine and deployed over the existing aortic valve [18]. The goal of hemodynamic management during the procedure is to achieve hemodynamic stability with stringent blood pressure control [19]. There is an application of rapid ventricular pacing (RVP) during the dilatation and positioning of the aortic valve prosthesis to ensure that the systolic blood pressure is kept low [20]. The RVP frequency is 180-200/min and a reduction in SAP to $50 \mathrm{mmHg}$ is considered adequate. RVP causes a cardiac standstill in order to minimize pulsatile trans-aortic flow, and thus the hypotension induced by RVP is very profound (in fact, it is almost comparable to cardiac arrest).

\subsection{Aim of the Study}

Various clinical conditions encountered under general anesthesia and surgical procedures such as hypotension, hemodynamic instability with hypovolemia, hypothermia, and cardiac arrest could cause changes in the EEG signal i.e., the changes in entropy parameters would incorrectly indicate that the hypnotic state had changed even though there was no actual alteration in the anesthesia level [21]. It is well known that the EEG signal is sensitive to the different artifacts present in the operating theatre environment such a diathermy, movement, and interference from electrical devices such as a heart pacemaker [22]. The physician should be aware of all of the patient's clinical conditions that exert a direct effect on EEG, since these could also directly influence the DoA value and subsequently lead to unreliable entropy values. In the literature, there are only a couple of case reports $[23,24]$ when the BIS monitor has been used during a sudden hemodynamic collapse or cardiac arrest; in those cases, BIS decreased significantly during the period of hemodynamic instability. As far as we are aware, the impact of the RVP on spectral entropy values under general anesthesia has not been systematically evaluated.

Therefore we hypothesized, based on the previous published data, that spectral entropy parameters derived from EEG would be significantly lowered during RVP, even though there was a steady level of anesthesia. The secondary objectives were to determine how the spectral entropy 
parameters, especially RE, react to a noxious stimulation during TAVI procedures. We also evaluated the patient's awareness during the anesthesia and his/her recall of intraoperative events using a standardized questionnaire.

\section{Experimental Section}

\subsection{Ethical Statements}

The study was approved by Ethics Committee of Kuopio University Hospital (identification code 133/08) and all patients provided written informed consent before they participated in the study. The study was conducted in accordance the last version of the Declaration of Helsinki. There were no exclusion criteria and no contraindications for general anesthesia were applied.

\subsection{Spectral Entropy Measures}

The M-ENTROPY ${ }^{\circledR}$ Module of the S/5 Anesthesia Monitor (GE, Healthcare, Helsinki, Finland) was used for the monitoring of entropy. After skin preparation but before anesthesia induction, the sensor with its three electrodes (GE Entropy Sensor, for single-patient use Ref: M1038681) was placed on the patient's forehead according to the manufacturer's guidelines. Unilateral placement was used with electrode 1 in the center of the frontal region approximately $4 \mathrm{~cm}$ above the nose, and electrode 3 in the right anterior temporal region between palpebral angle and the pileous line. Electrode 1 was an active (Fpz) electrode, electrode 2 was the ground electrode, and electrode 3 (F3) was the reference electrode. This referential measurement yields one channel of raw EEG data. The EEG signal was amplified, digitized and filtered by the software in the M-Entropy module. The module automatically checks that the electrode impedances are within an acceptable range before starting the measurement.

The electrode impedances were checked continuously and automatically by the module and were maintained under $5 \mathrm{k} \Omega$ during the measurement. If the impendence was high, conductive gel was used. A $15 \mathrm{~s}$ moving average window was used to calculate SE with the band-pass filtered $0.5-1800 \mathrm{~Hz}$. $\mathrm{SE}, \mathrm{RE}$ and a set of cardiopulmonary data (heart rate, systemic arterial blood pressures, central venous pressure, central and peripheral temperature, pulse oxymetry, airway pressure, and end-tidal $\mathrm{CO}_{2}$ ) were recorded continuously and transferred to a computer file using the Datex-Ohmeda S/5 Collect ${ }^{\mathrm{TM}}$ program. Computer and anesthesia monitor times were synchronized.

Clinical endpoints were recorded during the anesthesia and RE and SE values were analyzed off-line as the mean of $30 \mathrm{~s}$ at the 12 following time points (Figure 1): before induction of anesthesia and $1 \mathrm{~min}$ after, before intubation and after, before surgical stimulation and after, before use RVP for dilatation of aortic valve, during RVP and 1 min after, before RVP during positioning of the stent, during RVP, and 1 min thereafter.

Any signs of the patient's arousal such as a movement, coughing, or lacrimation were also noted. On the morning following the operation, all patients were interviewed for evaluation of awareness and recall of intraoperative events using a standard questionnaire [25].

\subsection{Rapid Ventricular Pacing}

In order to achieve rapid ventricular pacing, the pacing ball catheter (Bipolar Pacing Catheter, Edwards Lifesciences, Irvine, CA, USA) was introduced through the right jugular vein into the right ventricle and a standard external ventricular pacemaker (Medtronic 5388, Dual Chamber Temporary Pacemaker, Medtronic Inc., Minneapolis, MN, USA) was attached. The pacing ball location was accepted if the ventricular pacing threshold was under $0.5 \mathrm{~mA}$. The RVP was started by the anesthesiologist at a frequency of $180 / \mathrm{min}$ and was used twice during the procedure, once for dilatation of aortic valve, and the second time for positioning of the stent. The SAP was maintained over $120 \mathrm{mmHg}$ before the release of the stent, and during the positioning of valve prosthesis the goal 
was SAP under $50 \mathrm{mmHg}$. There were no changes in the anesthesia maintenance (propofol infusion) throughout the period of the RVP sequence.

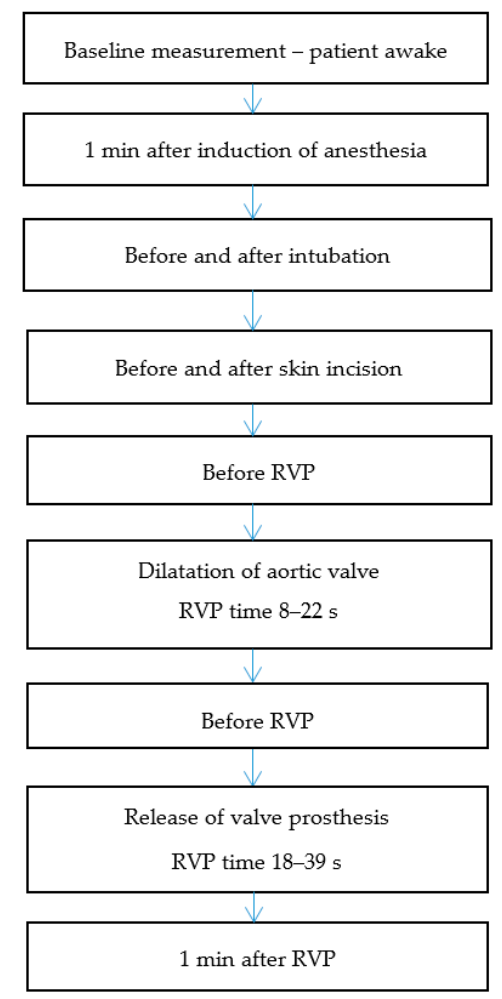

Figure 1. Block diagram of study protocol and time points of State Entropy, Response Entropy, and hemodynamic variables measurements. RVP—rapid ventricular pacing.

\subsection{General Anesthesia}

General anesthesia was standardized. All patients were premedicated with $0.1 \mathrm{mg} \cdot \mathrm{kg}^{-1}$ of diazepam one hour before the induction of anesthesia, and they also received their routine beta-blockers and long-acting nitrates. Total intravenous anesthesia (TIVA) was induced with $1.0-1.5 \mathrm{mg} \cdot \mathrm{kg}^{-1}$ of propofol, $2.0 \mu \mathrm{g} \cdot \mathrm{kg}^{-1}$ of fentanyl, and $0.1 \mathrm{mg} \cdot \mathrm{kg}^{-1}$ of cis-atracurium. After tracheal intubation, the lungs were ventilated with a mixture of oxygen and air (50\%) targeting an end-expiratory carbon dioxide level of 4.5-5.0 kPa. Anesthesia was maintained with infusion (2-8 mg/ kg/h) of propofol aiming at a SE value under 50. Neuromuscular blockade was tested with stimulation mode train-of-four (TOF) and the target during the operation was TOF 2 with an additional dose of cis-atracurium $0.03 \mathrm{mg} \cdot \mathrm{kg}^{-1}$ every $20 \mathrm{~min}$. Infusion of fentanyl of $2 \mu \mathrm{g} / \mathrm{kg} / \mathrm{h}$ with a rescue bolus dose of $1 \mu \mathrm{g} \cdot \mathrm{kg}^{-1}$ was used for analgesia.

\subsection{Statistical Analysis}

Data are reported as a means and standard deviations and range. Demographic and perioperative data are presented as the mean and range. Analysis of variance for repeated measures was used to detect significant changes in variables over time (ANOVA). The assumption of data normality was tested using the Kolmogorov-Smirnov test. The differences before and after time points were compared using Wilcoxon's Signed Rank Test and a $p$-value $<0.05$ was considered significant. All the statistical procedures were performed with the SPSS 22.0 statistical package for Windows (SPSS Inc., Chicago, IL, USA). The intubation and skin incision stimulation effect on spectral entropy parameters and hemodynamic variables was analyzed by Cohen's $d$ effect size defined as the difference between two means divided by the pooled standard deviation (small $d=0.2$; moderate $d=0.5$; large $d=0.8$ ). 


\section{Results}

Twenty one patients with a mean age of 80 years (range 68-87) were included in the study. The preoperative demographic and perioperative data of our study population are presented in Table 1. Fifty hours and forty minutes of data were collected and analyzed with 504 critical events. Spectral entropy values decreased significantly during the use of the RVP procedure and hypotension (Figure 2). Thus the value of SE declined from $28 \pm 13$ to $23 \pm 13$ during the RVP procedure; $(p<0.003)$, and from $29 \pm 12$ to $24 \pm 10(p<0.001)$. The corresponding values for RE were $29 \pm 13$ vs. $24 \pm 13$ $(p<0.006)$ and $30 \pm 12$ vs. $25 \pm 10(p<0.001)$. Both SE and RE values returned to the pre-RVP values after $1 \mathrm{~min}$. The mean time of RVP with a frequency of $185 \pm 9 / \mathrm{min}$ during the dilatation of the aortic valve was $16 \pm 4 ;(8-22 \mathrm{~s})$ and during the launch of the prosthesis the mean value was $24 \pm 6$; (18-39 s). The systolic blood pressure during RVP was under $50 \pm 5 \mathrm{mmHg}$. The hemodynamic data at different time points of the TAVI procedure is shown in Figure 3.

State entropy and response entropy

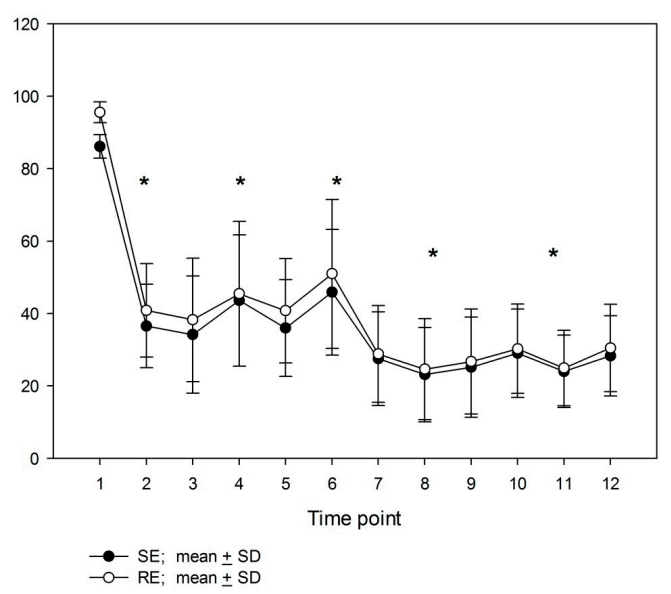

Figure 2. State entropy (SE) and response entropy (RE) at different time points of general anesthesia during the TAVI procedure. 1: baseline before induction of anesthesia; 2: $1 \mathrm{~min}$ after induction of anesthesia; 3: before intubation; 4: after intubation; 5: before skin incision; 6 : after skin incision, 7: before dilatation of aortic valve; 8: during dilatation of aortic valve with RVP; 9: 1 min after dilatation of aortic valve; 10: before release of valve prosthesis; 11: during release of valve prosthesis with RVP; 12: 1 min after release of aortic valve stent. Data are mean and $\pm \mathrm{SD}^{*}$ significant differences between the before and after time point.

Table 1. Clinical characteristics and perioperative data of study population.

\begin{tabular}{cc}
\hline Male/Female $(n)$ & $13 / 8$ \\
\hline Age $($ year $)$ & $80(68-87)$ \\
\hline Weight $(\mathrm{kg})$ & $75(56-111)$ \\
\hline Height $(\mathrm{cm})$ & $166(140-178)$ \\
\hline ASA classification & $4(3-4)$ \\
\hline LV ejection fraction $(\%)$ & $52(30-75)$ \\
\hline AV peak gradient $(\mathrm{mmHg})$ & $85(55-129)$ \\
\hline AVA $\left(\mathrm{cm}^{2}\right)$ & $0.5(0.2-0.8)$ \\
\hline Duration of anesthesia $(\mathrm{min})$ & $146(103-223)$ \\
\hline Total dosage of propofol $\left(\mathrm{mg} \cdot \mathrm{kg}^{-1}\right)$ & $6.7(4-12.6)$ \\
\hline Total dosage of fentanyl $\left(\mu \mathrm{gg} \cdot \mathrm{kg}^{-1}\right)$ & $5.8(3.1-7.6)$ \\
\hline
\end{tabular}

Data are mean, range or number of patients. ASA-American Society of Anesthesiologists; LV—left ventricular; $\mathrm{AV}-$ aortic valve; AVA-aortic valve area. 


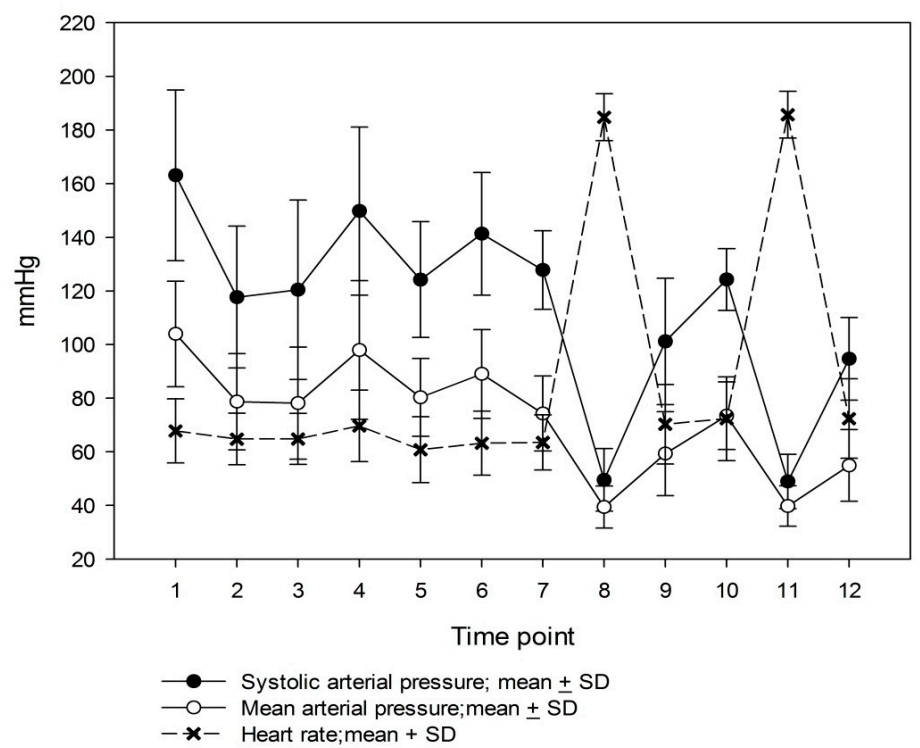

Figure 3. Hemodynamic variables, systolic arterial pressure, mean arterial pressure and heart rate at different time points during the TAVI procedure. For time points, see text in Figure 2.

Both spectral entropy parameters significantly increased after intubation (SE, $p<0.001$ and RE, $p<0.006$ ) and skin incision (SE and RE; $p<0.001$; Figure 2). Table 2 shows the values indicating the Cohen's $d$ effect of intubation and pain stimulation on the variables. Some signs of patient arousal were observed in 4 patients (14\%). In one patient, a movement reaction and lacrimation were noted after intubation and in the three other patients, only a movement reaction was evident after surgical stimulation even though there were low values of spectral entropy SE (mean $35 \pm 10$ ) and RE (mean $52 \pm 5$ ). No patient reported any recollection of intraoperative events.

Table 2. The polled Cohen's $d$ effect size statistics of the impact of intubation and surgical stimulation on response entropy (RE), state entropy (SE), and hemodynamic variables, systolic arterial pressure $(\mathrm{SAP})$, mean arterial pressure (MAP) and heart rate (HR).

\begin{tabular}{ccc}
\hline Variable & Intubation & Skin Incision \\
\hline RE & -0.37 & -0.63 \\
SE & -0.56 & -0.66 \\
SAP & -0.90 & -0.79 \\
MAP & -0.88 & -0.59 \\
HR & -0.44 & -0.16 \\
\hline Cohen's $d$ (small $d=0.2 ;$ moderate $d=0.5$; large $d=0.8)$.
\end{tabular}

\section{Discussion}

Our study is the first to reveal that abrupt hypotension due to RVP was able to induce changes in the EEG-based spectral entropy monitoring. The blood pressure drop during RVP decreased significantly spectral entropy values even though there were no simultaneous changes in the anesthesia maintenance (propofol infusion). They are only a few case reports when EEG-based monitoring has been used during the sudden hemodynamic collapse caused by cardiac arrest. The first report described a case of hypovolemic cardiac arrest during cardiac valve surgery when BIS was being used [23]. During sternotomy, the patient's right atrium was lacerated causing a sudden loss of blood volume. The SAP dropped to $20 \mathrm{mmHg}$ and $2 \mathrm{~min}$ after the sternotomy also BIS dropped to 5 with the BSR being almost $90 \%$. After the restoration of blood volume and pressure, BIS returned within $2 \mathrm{~min}$ 
to the pre-morbid level. In our study, the spectral entropy parameters returned more rapidly than the BIS, probably because of the inherent 30-60 s delay in the smoothing algorithm used to calculate BIS. In two patient cases [24], abrupt circulation collapses after cardiac surgery occurred in conscious patients who were being monitored for sedation by BIS; in the first patient the cardiovascular symptoms were attributable to asystole, while in the second patient they occurred during ventricular fibrillation (VF). The BIS value dropped to near zero in the first patient during the period of hemodynamic instability but increased to values around 40 within 2-3 min after the restoration of circulation. In the second patient with VF, when open cardiac massage was being performed, the value of BIS was below 25. After the restoration of circulation, BIS increased within two minutes to 45 , which is similar to our findings where the spectral entropy values increased after the termination of RVP. The authors concluded that the BIS may be an index of adequate cerebral perfusion during resuscitation. In a case report of cardiac arrest after cardiac surgery, the reduction in blood pressure was accompanied by a parallel drop in the BIS to a value of zero [26]. During the open heart resuscitation, BIS climbed back to the highest value 42 and then this gradually increased to a value of 60 at $15 \mathrm{~min}$ after resuscitation. The authors also concluded that BIS during resuscitation can provide the information about cerebral perfusion. In the case of reversible global cerebral hypoperfusion during Off-Pump CABG surgery, the BIS index suddenly declined from 45-50 down to zero during distal grafting of the coronary artery [27]. It was observed that the patient had low blood pressure at this instant, and after the restoration of normal hemodynamics, the BIS values returned to the values of 50 within $1 \mathrm{~min}$, which is in agreement with our findings. In the report of Goodman et al. [28], a BIS monitor was used during intraoperative cardiac arrest in two patients undergoing cardiothoracic surgery. In both patients during the cardiac arrest, the BIS value decreased from 40-50 to near zero, and remained low i.e., 10-20 after the resuscitation. A neurological deficit was found in the postoperative CT scan in both patients and the authors concluded that a BIS monitor can serve as a predictor of cerebral ischemic events occurring during surgery. In our previous study [15] comparing the spectral entropy and BIS values in the course of the general anesthesia for cardiac surgery, we observed that both values declined during the cannulation of aorta before cardiopulmonary bypass. Significant hypotension was associated with aorta cannulation which is in parallel with the present findings that abrupt hypotension can cause a reduction in the EEG-based anesthesia monitoring values.

EEG changes at the time of brief cardiac arrest during the testing of Implantable Cardioverter Defibrillator (ICD) device was assessed in 10 patients [29]. EEG changes were found at $10 \mathrm{~s}$ after the last heartbeat before the termination of ventricular fibrillation. Eighty two percent of EEG patterns were EEG slowing and attenuation of the amplitudes, considered to be a characteristic of cerebral ischemia. This parallels our findings, i.e., the RVP which lasted from $16 \pm 4 \mathrm{~s}$ to $24 \pm 6 \mathrm{~s}$ introduced changes in the spectral entropy parameters. The average SAP during ventricular fibrillation in their study was $28 \mathrm{mmHg}$ compared with $50 \mathrm{mmHg}$ here. The RVP evoked a cardiac arrest to minimize pulsatile trans-aortic flow and this caused a decrease in blood pressure. Hypotension reduces the cerebral blood flow $(\mathrm{CBF})$ and can lead to brain hypoxemia and the activation of neurovascular coupling mechanism. CBF changes are tightly linked to changes in neural activity through a complex sequence of coordinated events involving neurons, glia, and vascular cells, and hypotension caused reduction in neuronal activity [30]. This decrease of the synaptic transmission and action potentials and can lead to the changes in the EEG. The appearance of low frequency band power and overall decrease in amplitude and increase in in slow activity of EEG pattern was reported in case report after VF during the EEG monitoring [31]. The entropy algorithm interpreted the EEG slowing as deep anesthesia and the entropy parameters decreased. This correlation between cerebral perfusion and changes in the EEG patterns has also been detected in other EEG studies during carotid endarterectomy in 69 patients undergoing general anesthesia [32]. The processed EEG index decreased significantly following the clamping of the carotid artery which resulted in changes in the CBF. The EEG index was promptly restored to its original value after activation of the artery shunt and restoration of perfusion. 
The SE and RE values in our study also decreased to the same values immediately when the RVP was terminated.

$\mathrm{SE}$ and RE increased significantly after intubation as well as when there was noxious surgical stimulation. Cohen's $d$ effect size after intubation was higher for SE compared with RE, which was similar with the results in our previous study [15]. In this study in cardiac surgery patients, BIS was more affected than RE after intubation and was the better predictor of patient arousal.

In the current study, Cohen's $d$ effect size was only moderate for RE after skin incision, and the best predictor of noxious stimulation was SAP. In the study regarding RE responsiveness to pain stimulation, RE increased after surgical stimulation and was not dependent on recovery from muscle relaxation [14]. The authors suggest that RE reflects EMG and may be useful to identify inadequate anesthesia and patient arousal during painful stimuli. According to our results, however, the hemodynamic response was better.

In our previous study [15], the RE was found to be a better predictor of surgical stimulation than SE, EMG, and hemodynamic responses, especially after sternotomy. In our current study the RE response was only moderate. Sternotomy is much stronger noxious stimuli than only skin incision, and it can be the reason for a weak RE response.

Blood pressure was a very good indicator of patients arousal after intubation, and also surgical stimulation with large Cohen's $d$ effect. Heart rate was a poor indicator of painful stimulation; the heart rate did not significantly rise at any measurement time point. This result is probably attributable to the use of $\beta$-blockers in all patients.

In spite of the overall deep level of hypnosis in our patients, signs of arousal were noticed even though the SE value was 35. It was previously thought that unconsciousness and amnesia during general anesthesia were brain cortical phenomena [4]. However, according to the study of Långsjö et al. [33], subcortical structures of the brain are also involved during the emergence of consciousness during anesthesia. In that study, arousal-induced brain activation after propofol and dexmedetomidine anesthesia was visualized with PET. The emergence of consciousness, as assessed by the motor response to a spoken command, was associated with the activation of deep brain structures, involving subcortical and limbic regions that are functionally connected with parts of the frontal and inferior cortex. SE parameter of spectral entropy is delivered from frontal EEG and this may be the reason why no changes in the SE value were seen during arousal i.e., this parameter does not monitor activity in subcortical brain structures. This can be considered as a limitation of EEG based anesthesia monitoring since it only registers the cortical frontal EEG [4]. However, frontal muscles activation, measured by RE parameter, may indicate inadequate subcortical component of anesthesia. Facial muscles are not only voluntary, but also innervated by brainstem centers, and their activation is related to stress and nociception during general anesthesia [7]. This is probably a reason that RE values during patient's arousal, in the present study, were higher (52 \pm 5$)$, than $\mathrm{SE}$, because of the EMG activation. Even though four patients displayed signs of arousal during the general anesthesia, according our postoperative evaluation there was no recall of intraoperative events.

\section{Limitations of the Study}

The present study had several limitations. It was not a neurophysiological study and we did not collect or analyze any raw EEG data and so we have no information on what kind of changes occurred in the EEG during the period of hypotension caused by RVP. Some studies suggest that muscle relaxation may confound EEG-based DoA monitoring. In the study of Aho et al. [34] the increase in the RE after nociceptive stimulation was followed by increased SE in patients not receiving neuromuscular blockers. These increases were associated with the appearance of EMG in the EEG raw signal. Our study has limitation in this issue because we have no data of EMG, but there were no differences in TOF value between patients during the measurement points. 


\section{Conclusions}

In conclusion, the spectral entropy values decreased significantly during the RVP and the sub-sequent severe hypotension, even though there was no change in the anesthesia management. The severe hypotension results in a disturbance in the cerebral blood flow and EEG pattern. Those EEG changes were reflected in the spectral entropy parameters. Further studies are needed with EEG and spectral entropy monitoring in these kinds of patients to determine if there is any correlation between EEG changes occurring during hypotension and spectral entropy parameters.

Acknowledgments: The study was supported by the institutional grant (Number 5070209) from Kuopio University Hospital, Kuopio, Finland. The authors wish to thank research nurse Petri Toroi for his assistance in data acquisition.

Author Contributions: Tadeusz Musialowicz designed the study and it was his study idea; he recruited patients for the study, anesthetized patients for study, collected and analyzed the data, scrutinized the original study data, and wrote the first draft of the manuscript. Antti Valtola helped with the design of the study, recruited patients for study, and was involved in the surgical operations; he helped analyzed data and with the writing of manuscript. Mikko Hippeläinen helped in the design of the study, helped analyze the data and contributed to the writing of manuscript, recruited patients for the study, and was involved in the surgical operations. He also revised the manuscript. Jari Halonen helped in data analysis and preparing pictures, and helped with the writing of the manuscript. Pasi Lahtinen helped design the study, recruited and anesthetized patients in the study, helped in data analysis, reviewed and interpreted the data, and contributed to the writing of the manuscript. All of the authors read and approved the final version of manuscript.

Conflicts of Interest: The authors declare no conflict of interest.

\section{References}

1. Yli-Hankala, A. The effect of nitrous oxide on EEG spectral power during halothane and isoflurane anaesthesia. Acta Anaesthesiol. Scand. 1990, 34, 579-584. [CrossRef] [PubMed]

2. Jameson, L.C.; Sloan, T.B. Using EEG to monitor anesthesia drug effects during surgery. J. Clin. Monit. Comput. 2006, 20, 445-472. [CrossRef] [PubMed]

3. Chhabra, A.; Subramaniam, R.; Srivastava, A.; Prabhakar, H.; Kalaivani, M.; Paranjape, S. Spectral entropy monitoring for adults and children undergoing general anaesthesia. Cochrane Database Syst. Rev. 2016, 3, CD010135. [PubMed]

4. Musialowicz, T.; Lahtinen, P. Current Status of EEG-Based Depth-of-Consciousness Monitoring during General Anesthesia. Curr. Anesthesiol. Rep. 2014, 4, 251-260. [CrossRef]

5. Sigl, J.C.; Chamoun, N.G. An introduction to bispectral analysis for the electroencephalogram. J. Clin. Monit. 1994, 10, 392-404. [CrossRef] [PubMed]

6. Vakkuri, A.; Yli-Hankala, A.; Sandin, R.; Mustola, S.; Høymork, S.; Nyblom, S.; Talja, P.; Sampson, T.; van Gils, M.; Viertiö-Oja, H. Spectral entropy monitoring is associated with reduced propofol use and faster emergence in propofol-nitrous oxide-alfentanil anesthesia. Anesthesiology 2005, 103, 274-279. [CrossRef] [PubMed]

7. Nunes, R.R.; Almeida, M.P.; Sleigh, J.W. Spectral entropy: A new method for anesthetic adequacy. Rev. Bras. Anestesiol. 2004, 54, 404-422. [PubMed]

8. Viertiö-Oja, H.; Maja, V.; Särkelä, M.; Talja, P.; Tenkanen, N.; Tolvanen-Laakso, H.; Heimo, M.; Vakkuri, A.; Yli-Hankala, A.; Meriläinen, P. Description of The Entropy ${ }^{\mathrm{TM}}$ algorithm as applied in the Datex-Ohmeda S/5 ${ }^{\mathrm{TM}}$ Entropy Module. Acta Anaesthesiol. Scand. 2004, 48, 154-161. [CrossRef] [PubMed]

9. Wei, Q.; Liu, Q.; Fan, S.Z.; Lu, C.W.; Lin, T.Y.; Abbod, M.F.; Shieh, J.S. Analysis of EEG via Multivariate Empirical Mode Decomposition for Depth of Anesthesia Based on Sample Entropy. Entropy 2013, 15, 3458-3470. [CrossRef]

10. Valencia, J.F.; Melia, U.S.P.; Vallverdú, M.; Borrat, X.; Jospin, M.; Jensen, E.W.; Porta, A.; Gambús, P.L.; Caminal, P. Assessment of Nociceptive Responsiveness Levels during Sedation-Analgesia by Entropy Analysis of EEG. Entropy 2016, 18, 103. [CrossRef]

11. Rosso, O.A. Entropy changes in brain function. Int. J. Psychophysiol. 2007, 64, 75-80. [CrossRef] [PubMed] 
12. Vakkuri, A.; Yli-Hankala, A.; Talja, P.; Mustola, S.; Tolvanen-Laakso, H.; Sampson, T.; Viertiö-Oja, H. Time-frequency balanced spectral entropy as a measure of anesthetic drug effect in central nervous system during sevoflurane, propofol, and thiopental anesthesia. Acta Anaesthesiol. Scand. 2004, 48, 145-153. [CrossRef] [PubMed]

13. Särkelä, M.; Mustola, S.; Seppänen, T.; Koskinen, M.; Lepola, P.; Suominen, K.; Juvonen, T.; Tolvanen-Laakso, H.; Jäntti, V. Automatic analysis and monitoring of burst suppression in anesthesia. J. Clin. Monit. Comput. 2002, 17, 125-134. [CrossRef] [PubMed]

14. Wheeler, P.; Hoffman, W.E.; Baughman, V.; Koeing, H. Response entropy increases during painful stimulation. J. Neurosurg. Anesthesiol. 2005, 17, 86-90. [CrossRef] [PubMed]

15. Musialowicz, T.; Lahtinen, P.; Pitkänen, O.; Kurola, J.; Parviainen, I. Comparison of spectral entropy and BIS VISTA ${ }^{\mathrm{TM}}$ monitor during general anesthesia for cardiac surgery. J. Clin. Monit. Comput. 2011, 25, 95-103. [CrossRef] [PubMed]

16. Lefevre, T.; Kappetain, A.; Wolner, E.; Nataf, P.; Thomas, M.; Schächinger, V.; De Bruyne, B.; Eltchaninoff, H.; Thielmann, M.; Himbert, D.; et al. One year follow-up of the multi-centre European PARTNER transcatheter heart valve study. Eur. Heart J. 2010, 32, 148-157. [CrossRef] [PubMed]

17. Smith, C.R.; Leon, M.B.; Mack, M.J.; Miller, D.C.; Moses, J.W.; Svensson, L.G.; Tuzcu, E.M.; Webb, J.G.; Fontana, G.P.; Makkar, R.R.; et al. PARTNER Trial Investigators. Transcatheter versus surgical aortic-valve replacement in high-risk patients. N. Engl. J. Med. 2011, 364, 2187-2198. [CrossRef] [PubMed]

18. Indraratna, P.; Tian, D.H.; Yan, T.D.; Doyle, M.P.; Cao, C. Transcatheter aortic valve implantation versus surgical aortic valve replacement: A meta-analysis of randomized controlled trials. Int. J. Cardiol. 2016, 224, 382-387. [CrossRef] [PubMed]

19. Kratzert, W.B.; Mladenow, A.; Boyd, E.K.; Komal, P. Perioperative Management of Transcatheter Aortic Valve Replacement: Current Advancements and Controversies. Curr. Anesthesiol. Rep. 2015, 5, 474-481. [CrossRef]

20. Webb, J.; Pasupati, S.; Achtem, L.; Thompson, C.H. Rapid pacing to facilitate transcatheter prosthetic heart valve implantation. Catheter. Cardiovasc. Interv. 2006, 68, 199-204. [CrossRef] [PubMed]

21. Dahaba, A.A. Different conditions that could result in the bispectral index indicating an incorrect hypnotic state. Anesth. Analg. 2005, 101, 765-773. [CrossRef] [PubMed]

22. Hemmerling, T.M.; Charabati, S.; Bracco, D. Unusual case of low bispectral index values due to electrocardiographic interferences. Br. J. Anaesth. 2008, 101, 877-888. [CrossRef] [PubMed]

23. England, M.R. The Changes in Bispectral Index during a Hypovolemic Cardiac Arrest. Anesthesiology 1999, 91, 1947. [CrossRef] [PubMed]

24. Chakravarthy, M.; Patil, T.; Jayaprakash, K.; Shivananda, N.; Jawali, V. Bispectral index is an indicator of adequate cerebral perfusion during cardiopulmonary resuscitation. J. Cardiothorac. Vasc. Anesth. 2003, 17, 506-508. [CrossRef]

25. Apfelbaum, J.L.; James, F.; Arens, J.F.; Cole, D.J.; Connis, R.T.; Domino, K.B.; Drummond, J.C.; Kalkman, C.J.; Miller, R.D.; Nickinovich, D.G.; et al. American Society of Anesthesiologists Task Force on Intraoperative Awareness. Practice advisory for intraoperative awareness and brain function monitoring: A report by the American Society of Anesthesiologists task force on intraoperative awareness. Anesthesiology 2006, 104, 847-864.

26. Azim, N.; Wang, C.Y. The use of bispectral index during a cardiopulmonary arrest: A potential predictor of cerebral perfusion. Anaesthesia 2004, 59, 610-612. [CrossRef] [PubMed]

27. Hemmerling, T.M.; Olivier, J.F.; Basile, F.N.; Prieto, I. Bispectral index as an indicator of cerebral hypoperfusion during off-pump coronary artery bypass grafting. Anesth. Analg. 2005, 100, 354-356. [CrossRef] [PubMed]

28. Goodman, P.G.; Mehta, A.R.; Castresana, M.R. Predicting ischemic brain injury after intraoperative cardiac arrest during cardiac surgery using the BIS monitor. J. Clin. Anesth. 2009, 21, 609-612. [CrossRef] [PubMed]

29. Clute, H.L.; Levy, W.I. Electroencephalographic Changes during Brief Cardiac Arrest in Humans. Anesthesiology 1990, 11, 821-825. [CrossRef]

30. Shmuel, A.; Yacoub, E.; Pfeuffer, J.; Van de Moortele, P.F.; Adriany, G.; Hu, X.; Ugurbil, K. Sustained negative BOLD, blood flow and oxygen consumption response and its coupling to the positive response in the human brain. Neuron 2002, 36, 1195-1210. [CrossRef] 
31. Westerén-Punnonen, S.M.; Yppärilä, H.; Musialowicz, T.; Korhonen, I.; Hynynen, M.; Partanen, J. Recovery of N100 component of auditory event-related potentials and EEG after cardiac arrest during propofol sedation. Br. J. Anaesth. 2005, 94, 626-629. [CrossRef] [PubMed]

32. Perez, W.; Dukatz, C.; El-Dalati, S.; Duncan, J.; Abdel-Rasoul, M.; Springer, A.; Go, M.R.; Dzwonczyk, R. Cerebral oxygenation and processed EEG response to clamping and shunting during carotid endarterectomy under general anesthesia. J. Clin. Monit. Comput. 2015, 6, 713-720. [CrossRef] [PubMed]

33. Långsjö, J.W.; Alkire, M.T.; Kaskinoro, K.; Hayama, H.; Maksimow, A.; Kaisti, K.K.; Aalto, S.; Aantaa, R.; Jääskeläinen, S.K.; Revonsuo, A.; et al. Returning from oblivion: Imaging the neural core of consciousness. J. Neurosci. 2012, 32, 4935-4943. [PubMed]

34. Aho, A.J.; Yli-Hankala, A.; Lyytikäinen, L.P.; Jäntti, V. Facial muscle activity, Response Entropy, and State Entropy indices during noxious stimuli in propofol-nitrous oxide or propofol-nitrous oxide-remifentanil anaesthesia without neuromuscular block. Br. J. Anaesth. 2009, 102, 227-233. [CrossRef] [PubMed]

(C) 2017 by the authors. Licensee MDPI, Basel, Switzerland. This article is an open access article distributed under the terms and conditions of the Creative Commons Attribution (CC BY) license (http:/ / creativecommons.org/licenses/by/4.0/). 